\title{
EXCLUSÃO GASTRODUODENAL E VAGOTOMIA TRONCULAR: REPERCUSSÃO NO PESO CORPORAL E GASTRINEMIA - ESTUDO EXPERIMENTAL EM RATOS
}

\author{
GASTRODUODENAL EXCLUSIONAND TRUNCAL VAGOTOMY: WEIGHT AND \\ SERIC GASTRIN ALTERATIONS - EXPERIMENTAL STUDY ON RATS
}

\author{
Pedro Luiz Squilacci Leme, TCBC-SP ${ }^{1}$ \\ Carlos Alberto Malheiros, TCBC-SP ${ }^{2}$ \\ Francisco Cesar Martins Rodrigues, TCBC-SP2 \\ Andréia Bonizzia Zanqui ${ }^{3}$ \\ Darcy Lisbão Moreira de Carvalho - ACBC-SP ${ }^{4}$ \\ Fares Rahal, ECBC-SP5
}

\begin{abstract}
RESUMO: Objetivo: A obesidade mórbida é uma doença crônica que se acompanha de várias complicações médicas e de uma menor esperança de vida, prejudicando o aspecto físico, emocional, econômico e social. As pesquisas clínicas e experimentais são amplamente justificadas nesta doença, considerando-se que a opção de tratamento operatório é recente. As gastroplastias e as derivações gástricas são algumas das modalidades terapêuticas propostas e produzem uma grande câmara gástrica remanescente, que em algumas técnicas fica totalmente excluída do trânsito alimentar. As possíveis alterações deste segmento, transformado em apêndice do sistema digestório, representam um vasto campo para pesquisa. Tivemos como objetivo avaliar o peso e as alterações da dosagem de gastrina sérica do rato, após denervação vagal troncular subdiafragmática, com exclusão da câmara gástrica e duodeno do trânsito alimentar do animal. Método: Foi realizada vagotomia troncular e exclusão gastroduodenal em cem ratos, dos quais trinta puderam ser estudados. Eram ratos machos adultos (Rattus Norvegicus Albinus), da linhagem Wistar, com peso médio de 378,67 g. Este estudo foi complementado pela dosagem sérica de gastrina por radioimunoensaio com $\mathrm{I}^{125}$ e duplo anticorpo para gastrina. Resultados: $\mathrm{O}$ peso de todos os ratos estudados diminuiu em média de 378,67 g para 285,83 g. Os trinta animais perderam em média 92,83 g (-24,52\%). Houve diferenças significativas entre o peso inicial dos animais e o peso final $(\mathrm{p}<0,001)$. A gastrina sérica também diminuiu em vinte e um dos trinta ratos operados, caindo de 59,68 pg/ml para 46,77 pg/ml em média, correspondendo a uma diminuição de 12,91 pg (-19,73\%) entre as duas médias ( $\mathrm{p}<0,001)$. A análise estatística teve como objetivo avaliar se houve diminuição nas médias das variáveis: peso e gastrina, medidas antes e depois da operação proposta. Para avaliar as diferenças entre as médias, utilizou-se o teste estatístico do T-Student.Conclusões: Houve uma diminuição significativa do peso e da dosagem de gastrina sérica do animal.
\end{abstract}

Descritores: Gastroplastia; Gastrinas; Derivação gástrica; Vagotomia troncular; Modelos animais.

\section{INTRODUÇÃO}

O tratamento operatório da obesidade mórbida evoluiu nos últimos quarenta anos, sendo cada vez mais estudado e novas variantes técnicas são propostas com freqüência. Embora não seja a terapêutica ideal, atualmente representa a única opção para uma perda efetiva do peso, mantida a longo prazo.

1. Professor Assistente, Faculdade de Ciências Médicas da Santa Casa de São Paulo

2. Professor Adjunto, Doutor, Faculdade de Ciências Médicas da Santa Casa de São Paulo.

3. Bióloga, Faculdade de Ciências Médicas da Santa Casa de São Paulo.

4. Doutor em Cirurgia, Faculdade de Ciências Médicas da Santa Casa de São Paulo

5. Professor Titular, Livre-docente, Faculdade de Ciências Médicas da Santa Casa de São Paulo.

Recebido em 08/07/2002

Aceito para publicação em 17/12/2002

Trabalho realizado no Departamento de Cirurgia da Faculdade de Ciências Médicas da Santa Casa de São Paulo. 
As pesquisas clínicas e experimentais são amplamente justificadas nesta doença, considerandose que os conceitos e o desenvolvimento do tratamento operatório são recentes. Novos estudos estão sendo realizados em várias áreas, mostrando que o assunto não está esgotado e modelos experimentais podem contribuir para a compreensão das alterações da fisiologia gástrica.

Diferente de outros tecidos endócrinos, as células intestinais que contém hormônios estão distribuídas difusamente na mucosa de uma ou mais regiões do sistema digestório. Atualmente, o intestino é considerado o maior órgão endócrino do corpo, tendo sido reconhecidos nos últimos anos mais de vinte sistemas hormonais e de peptídeos gastrointestinais reguladores, representando uma das áreas mais pesquisadas em alguns países ${ }^{1}$.

A gastrina é o hormônio gastrointestinal mais bem estudado. Sua existência foi prevista por Edkins em 1905, mas apenas na década de 1960 Gregory e Tracy conseguiram uma gastrina pura o suficiente para permitir a análise de sua cadeia de aminoácidos, o que permitiu a McGuigan em 1968, preparar anticorpos que permitiram o radioimunoensaio da gastrina circulante e a identificação das células que a produzem e que aparecem principalmente na mucosa antral $^{1,2}$. A ação biológica identificável da gastrina é a estimulação de secreção ácida pelo estômago, assim como a secreção de pepsina, mas esta ação poderia ser secundária ao seu efeito sobre o ácido. Outra ação biológica importante seria estimular o crescimento da mucosa secretora de ácido do estômago e também da mucosa do intestino delgado e do cólon ${ }^{3-5}$. A liberação de gastrina no ser humano obedece a vários estímulos alimentares e químicos. O principal inibidor fisiológico da liberação da gastrina é a concentração de íon hidrogênio no estômago, assim como a somatostatina. Existe uma correlação importante entre a gastrina e a somatostatina, sendo necessário elucidar os diferentes sistemas neuro-hormonais aqui envolvidos ${ }^{6}$. Muitos estudos experimentais foram realizados para evidenciar melhor a ação da gastrina, mas existem vários pontos ainda obscuros a serem estudados.

Os mecanismos que determinam a secreção gástrica após a ingestão alimentar são vários: estímulo cefálico, estímulo vagal das células parietais, liberação de gastrina pelo antro, distensão gástrica e o estímulo químico produzido por alguns polipeptídeos e amino-ácidos para a liberação de gastrina ${ }^{7}$.
Sabe-se que a vagotomia troncular induz à hiperplasia das células $\mathrm{G}$ antrais, que se desenvolve após hipocloridria prolongada e também a um aumento do número de células $\mathrm{G}$, sem interferir em sua atividade, provocando um aumento da concentração de gastrina basal e pós-prandial ${ }^{8}$. Esta hiperplasia se deveria à ativação de células $G$ já existentes, com alterações ultra-estruturais demonstráveis no Complexo de Golgi e retículo endoplasmático ${ }^{9}$. Lopasso et al ${ }^{10}$, em 1999, não encontraram hiperplasia destas células quando estudaram, a longo prazo, ulcerosos duodenais submetidos à vagotomia gástrica proximal.

Após as derivações gástricas para o tratamento da obesidade, não ocorre alteração da gastrina basal e da gastrina estimulada pela alimentação ou hipoglicemia, não sendo habitual o aparecimento de úlcera péptica (1 a $2 \%$ ), após estas derivações. A falta de contato com os alimentos e uma denervação vagal não intencional que ocorre durante a operação podem explicar parcialmente estes dados ${ }^{11}$.

Estudos com ratos geneticamente obesos (Zucker), mostram que a hiperfagia apresentada por estes animais estimularia a hiperplasia das células $\mathrm{G}$ e a restrição alimentar reduziria as células $\mathrm{G}$ do antro gástrico a níveis similares aos ratos não obesos. Embora o comportamento alimentar anormal destes animais não seja a causa primária, estes autores mostraram a complexidade dos fatores que interferem na atividade das células $\mathrm{G}$ e produção de gastrina ${ }^{12}$. O número de células endócrinas do estômago é controlado por vários fatores. A densidade das células G e D depende da presença ou ausência de alimentos, do $\mathrm{pH}$ antral, de fatores hormonais e neurais, mas estes fenômenos são apenas parcialmente compreendidos ${ }^{13}$.

As gastroplastias e as derivações gástricas são algumas das modalidades de tratamento operatório propostas para a obesidade mórbida e produzem uma grande câmara gástrica remanescente, que em algumas técnicas, fica totalmente excluída do trânsito alimentar, sendo muitas vezes impossível seu estudo endoscópico habitual ${ }^{14}$. As possíveis alterações deste segmento, transformado em apêndice do sistema digestório, representam um vasto campo para pesquisa, justificando o desenvolvimento de modelos experimentais, que com todas as suas limitações, podem contribuir com o estudo da fisiologia gástrica em animais. No século passado, as bolsas gástricas clássicas, inervadas ou não, do fundo, do antro ou de todo o estômago, despertaram a atenção dos fisiologistas e 
atualmente, este recurso pode fornecer dados relevantes sobre as funções digestivas.

Criando um modelo de exclusão gastroduodenal, com este segmento do tubo digestivo denervado e submetido apenas a estímulo endócrino, sem alimentos ou refluxo da secreção biliar e pancreática, tivemos como objetivo avaliar o peso corporal e as alterações da dosagem de gastrina sérica do rato.

\section{MÉTODO}

Este estudo foi previamente aprovado pelo Comitê de Ética em Pesquisa Experimental da Faculdade de Ciências Médicas da Santa Casa de São Paulo e seguiu as normas da Unidade de Técnica Cirúrgica e Cirurgia Experimental, onde foi realizado. Incluindo o projeto piloto do estudo, de um total de cem ratos operados, puderam ser utilizados trinta ratos machos adultos (Rattus Norvegicus Albinus), da linhagem Wistar, com peso médio de $378,67 \mathrm{~g}$, provenientes do biotério da Faculdade de Ciências Médicas da Santa Casa de São Paulo. As operações foram realizadas na Unidade de Técnica Cirúrgica e Cirurgia Experimental da mesma instituição. As dosagens de gastrina foram realizadas no Laboratório Nuclimagem e a análise estatística no Laboratório de Epidemiologia e Estatística do Instituto Dante Pazzanese.

Os animais permaneceram em gaiolas individuais, com livre acesso à água e ração padronizada. Nas doze horas que precederam a operação permaneceram em jejum e nas primeiras vinte e quatro horas subseqüentes receberam solução aquosa de sacarose a dez por cento, sendo então novamente liberada a ração habitual seca e umedecida em solução de sacarose. Foram medidos e pesados no dia da operação e da reoperação, que foi realizada entre vinte e um e vinte e oito dias de pós-operatório, quando os animais foram mortos.

A anestesia foi realizada com cloridrato de 2-(0-clorofenil)-2-(metilamino) ciclohexanona (Ketamina ${ }^{\circledR}$ ), na dosagem de 6 a $10 \mathrm{mg} / \mathrm{kg}$, associado ao cloridrato de 2-(2,6-xilidino)-5,6-dihidro-4H-1,3tiazina (Xilazina ${ }^{\circledR}$ ), na dosagem de $0,1 \mathrm{mg} / \mathrm{kg}$, injetados na cavidade abdominal. Os animais anestesiados eram medidos e pesados, sendo realizada tricotomia e incisão mediana com aproximadamente quatro centímetros de extensão. Após a abertura da cavidade abdominal, a veia cava inferior era visualizada e puncionada próximo da desembocadura das veias renais, sendo aspirados dois mililitros de sangue.

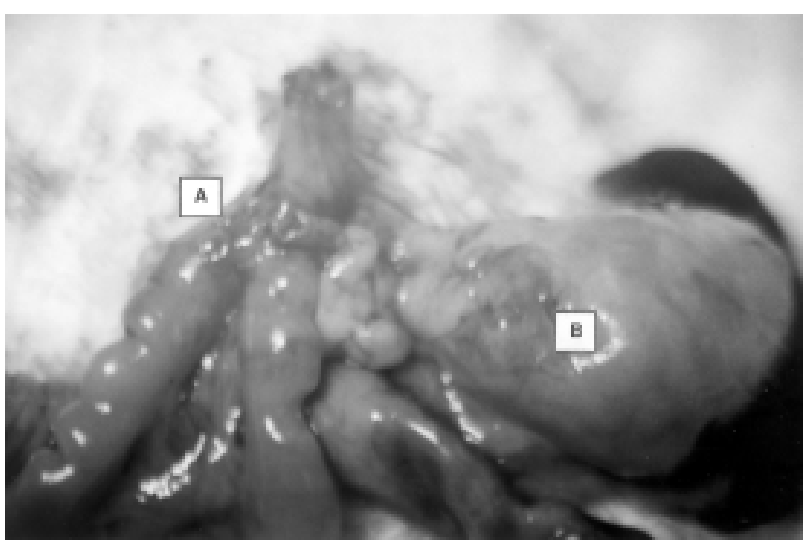

Figura 1 - Modelo experimental de exclusão gastroduodenal e vagotomia troncular bilateral subdiafragmática, com reconstrução do trânsito alimentar através de anastomose esofago-jejunal término-lateral (A), anterior à câmara gástrica excluída (B).

O estômago era exposto e o esôfago era dissecado, seccionado e com ele os dois troncos dos nervos vagos, a cárdia era fechada com chuleio simples, usando fio monofilamentar de polipropileno 6-0. Realizava-se anastomose esofago-jejunal, término-lateral, em um plano de sutura (chuleio simples), com fio de polipropileno 6-0. A anastomose, na primeira alça jejunal (aproximadamente cinco centímetros após o final do duodeno), alcançava o esôfago anteriormente à câmara gástrica, que era mantida em sua posição habitual (Figura 1). A cavidade abdominal era fechada com dois planos de sutura, usando fio de náilon monofilamentar 5-0, também com um chuleio simples no plano muscular e outro na pele do animal. $\mathrm{O}$ abdome era preenchido com cinco mililitros de solução salina a $0,9 \%$ durante seu fechamento.

$\mathrm{O}$ sangue retirado do animal era mantido em tubo seco, aguardando-se trinta minutos para sua coagulação e retração do coágulo, sendo então centrifugado por dez minutos para obtenção de pelo menos meio mililitro de soro, que era imediatamente congelado; neste soro posteriormente foi dosada a gastrina do rato, usada como controle.

Os animais eram mantidos em gaiolas individuais e trinta animais sobreviventes foram reoperados entre a terceira e a quarta semana de pós-operatório. Após um prazo mínimo de vinte e um dias, os animais eram mantidos em jejum noturno de doze horas, novamente anestesiados com a mesma técnica, medidos e pesados, sendo realizada incisão mediana xifo-púbica. A veia cava inferior era novamente visualizada e puncionada, sendo aspirado todo o sangue possível, aproximadamente nove mililitros, provocando a morte do rato por hipovolemia. 
O sangue retirado seguia a mesma rotina anterior de centrifugação e retirada do soro, que era congelado.

A gastrina sérica foi dosada por radioimunoensaio com $\mathrm{I}^{125}$ e duplo anticorpo para gastrina, fornecido pelo laboratório DPC (Diagnostic Products Corporation), com a denominação KGAD1®. Cada estojo contém menos que 3.0 microcuries, o equivalente a 111 kilobecquerels de iodo radioativo ( $\mathrm{I}^{125}$ Gastrina). A dosagem da gastrina sérica foi realizada no laboratório Nuclimagem, sendo usados reagentes de preparado comercial para estudo de duplo anticorpo para gastrina. Os exames foram realizados todos no mesmo dia, pelo mesmo técnico, usando os mesmos reagentes e a mesma curva de calibragem do aparelho, baseado nos controles de qualidade habituais do laboratório e expresso em picogramas por mililitro ( $\mathrm{pg} / \mathrm{ml})$.

Para avaliar as diferenças entre as médias, utilizou-se o teste estatístico do T-Student para dados pareados, já que comparamos o mesmo rato antes e após a operação, levando-se em consideração que estamos tratando da mesma amostra e que esta pode estar sujeita a erros. O p-valor significa a probabilidade de se cometer um erro, chamado de erro tipo II (probabilidade de se dizer que as médias são diferentes, quando na verdade, são iguais). Se temos esta probabilidade inferior a 0,05 ou $5 \%$ (nível de significância), podemos dizer que as médias são diferentes.

\section{RESULTADOS}

O peso de todos os ratos estudados diminuiu em média de $378,67 \mathrm{~g}$ para $285,83 \mathrm{~g}$. Os trinta animais perderam em média 92,83 g (-24,52\%). Houve diferenças significativas entre o peso inicial dos animais e o peso final $(\mathrm{p}<0,001)$ - Tabela 1 .

A gastrina sérica também diminuiu em vinte e um dos trinta ratos operados, caindo de 59,68 pg/ml para $46,77 \mathrm{pg} / \mathrm{ml}$ em média, correspondendo a uma diminuição de 12,91 pg (-19,73\%) entre as duas médias $(\mathrm{p}<0,001)$ - Tabela 1.

A porcentagem de queda do peso $(-24,52 \%)$ e queda da gastrina $(-19,73 \%)$ não apresentaram uma correlação significativa (p 0,37) - Tabela 2 .

A Figura 2 compara as médias (dados pareados) entre as porcentagens de queda de peso e queda de gastrina, que não foi significativa (p 0,161). Foram criadas variáveis para avaliar esta diminuição percentual do peso e da gastrina sérica. A análise

Tabela 1 - Comparação entre a média (dados pareados) e o teste T-Student (pareado), avaliando o peso e a gastrina sérica.

\begin{tabular}{cccccc}
\hline & Média & N (ratos) & $\begin{array}{c}\text { Desvio } \\
\text { padrão }\end{array}$ & $\begin{array}{c}\text { Média } \\
\text { de erro }\end{array}$ & p-valor \\
\hline 1 Peso inicial $(\mathrm{g})$ & 378,67 & 30 & 72,65 & 13,26 & \\
Peso final $(\mathrm{g})$ & 285,83 & 30 & 68,91 & 12,58 & $<0,001$ \\
& & & & & \\
2 Gastrina inicial $(\mathrm{pg} / \mathrm{ml})$ & 59,68 & 30 & 12,9176 & 2,36 & \\
Gastrina final $(\mathrm{pg} / \mathrm{ml})$ & 46,77 & 30 & 14,3415 & 2,62 & $<0,001$ \\
\hline
\end{tabular}

Tabela 2 - Comparação entre a média (dados pareados) e o teste T-Student (pareado), avaliando a porcentagem (\%) de queda de peso e de gastrina sérica.

\begin{tabular}{lccccc}
\hline & Média & N (ratos) & $\begin{array}{c}\text { Desvio } \\
\text { padrão }\end{array}$ & $\begin{array}{c}\text { Média } \\
\text { de erro }\end{array}$ & p-valor \\
\hline $1 \%$ de queda de peso & $-24,52$ & 30 & 9,96 & 1,82 & \multicolumn{1}{c}{0,37} \\
$2 \%$ de queda de gastrina & $-19,73$ & 30 & 24,78 & 4,52 & $(\mathrm{NS})$ \\
\hline
\end{tabular}




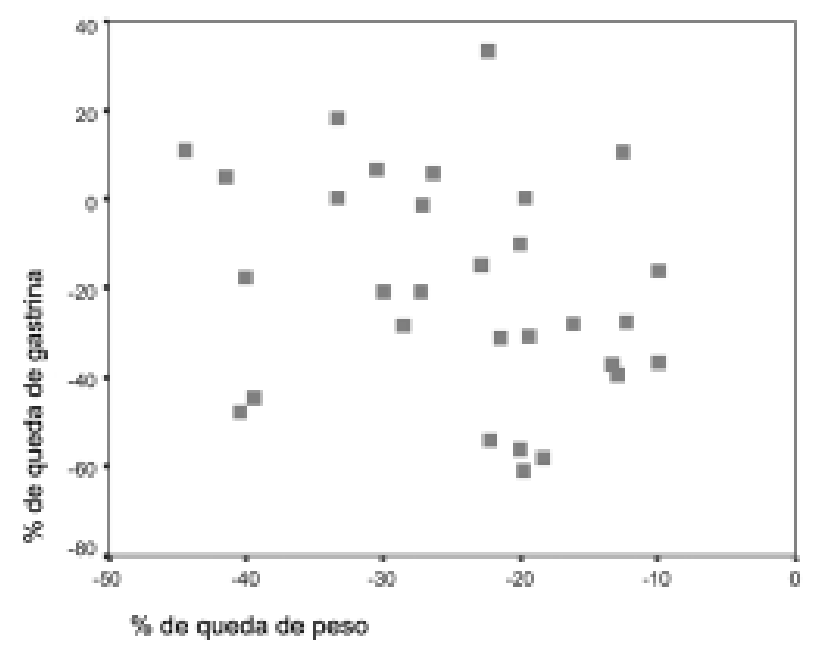

Figura 2 - Porcentagem (\%) de queda da gastrina sérica e de peso dos trinta ratos estudados $(p$ 0,161). Cada marca representa um rato.

estatística teve como objetivo demonstrar se houve diminuição significativa nas médias destas variáveis. A correlação é a medida da relação linear entre as duas variáveis quantitativas, avaliando se à medida que uma vai crescendo, a outra vai diminuindo (ou aumentando) proporcionalmente. Neste estudo não houve correlação linear entre as porcentagens estudadas.

\section{DISCUSSÃO}

O uso das bolsas de partes do estômago ${ }^{15}$, do antro ou fundo gástrico, inervadas ou não, sempre despertaram a atenção dos pesquisadores e contribuíram para o estudo da secreção gástrica (bolsas de Pavlov ou Heidenhaim). Ainda hoje, com técnicas mais precisas para as dosagens de hormônios e dos peptídeos intestinais, estes experimentos permanecem atuais. Cada vez mais são estudados os sistemas que envolvem as fibras nervosas colinérgicas e as que contém o peptídeo liberador de gastrina (GRP), assim como a somatostatina e os peptídeos que a liberam ${ }^{9}$. A exclusão gástrica total proposta permite vários enfoques para a pesquisa e também elimina o efeito dos alimentos sobre o estômago, mantendo a continuidade do trato gastrointestinal.

Sclafani ${ }^{16}$, em 1987, estudou os efeitos da cirurgia gastrointestinal no comportamento dos animais quanto à ingestão alimentar, mostrando que pode haver um impacto maior após as derivações intestinais e a vagotomia. Estes dois procedimentos reduziriam a ingestão alimentar e o peso nos animais obesos de modo mais acentuado do que nos animais magros. Da mesma forma, estes parâmetros diminuiriam mais nos ratos obesos por lesão do hipotálamo do que nos ratos geneticamente obesos. Esta alteração da ingestão alimentar pode se fazer de forma direta, por alteração de mecanismos neurais e hormonais ou indiretamente, por modificação do fluxo de nutrientes ou de sua absorção $0^{16}$.

Furness et $a l^{17}$, em 2001, também demonstraram que a vagotomia troncular isolada já é suficiente para reduzir a ingestão da dieta e levar a perda de peso em humanos e animais de laboratório. Estes autores mostraram que ratos apresentavam uma diminuição da ingestão diária de ração e perdiam massa de gordura. A perda foi próxima $20 \%$ quatro semanas após a vagotomia e este efeito poderia ser devido a perda de vias aferentes vagais, que despertam o apetite ou poderiam ocorrer mudanças endócrinas, como o aumento da produção de hormônio da saciedade. Os animais que estudamos perderam em média $24,52 \%$ do peso durante este estudo e a vagotomia foi apenas um dos procedimentos operatórios realizados.

Hirschowitz e Fong ${ }^{18}$ demostraram que a denervação vagal seletiva do antro de cães reduz a liberação de gastrina. Higham et $a l^{19}$, usando o mesmo princípio de denervação vagal do antro de ratos, notaram que a distensão mecânica do estômago é suficiente para liberar gastrina. Como estes mecanismos são complexos e sujeitos a muitas variáveis, procuramos evitar qualquer estímulo vagal no estômago excluído (denervação do corpo e antro), assim como contamos com a não distensão da câmara gástrica excluída.

Poderíamos questionar se a desnutrição apresentada pelo animal interferiria na dosagem de gastrina sérica. Koop et $a l^{20}$ estudaram os efeitos do jejum prolongado sobre a liberação de gastrina e somatostatina em um modelo de estômago isolado, vascularizado e perfundido. $\mathrm{O}$ jejum de três dias produziu uma diminuição da gastrina antral, mas não alterou a somatostatina neste modelo experimental. As células $\mathrm{G}$ responderam à infusão de acetilcolina e bombesina, embora com valores menores do que os da gastrina basal. Este estudo mostrou que as células mantiveram sua capacidade funcional.

Lopasso et $a l^{10}$, estudando a longo prazo (11 a 22 anos após), ulcerosos duodenais submetidos à 
vagotomia gástrica proximal, encontraram valores aumentados da gastrina sérica dosada em jejum, tantos nos doentes com recidiva da úlcera duodenal, quanto naqueles onde não havia recidiva; mas a hiperplasia das células $\mathrm{G}$ não foi demonstrada em nenhum desses grupos.

A ação da gastrina é estimular a secreção ácida do estômago e talvez também a de pepsina. Outra ação importante é estimular o crescimento da mucosa secretora de ácido do estômago. A administração prolongada de doses farmacológicas de gastrina leva a uma hiperplasia da região de glândulas oxínticas do estômago. Doses elevadas levam a um aumento na síntese de DNA, RNA e proteína na mucosa ${ }^{6}$. Em nosso estudo, a vagotomia realizada e a exclusão gástrica podem ter interferido nas fases cefálica e gástrica da digestão, contribuindo com esta menor dosagem de gastrina sérica encontrada.

Segundo Grossman ${ }^{21}$, a gastrina é um hormônio gastrointestinal maior. Existe em algumas formas moleculares que diferem uma da outra pelo comprimento do polipeptídeo de sua molécula, assim como pelo arranjo individual de seus aminoácidos. Apresenta-se em três formas principais, G-17, G-34 e G-14, recebendo esta denominação em função do número de aminoácidos. A gastrina avaliada quantitativamente no soro dos ratos deste estudo foi dosada por radioimunoensaio ( $\mathrm{I}^{125}$, Duplo Anticorpo Gastrina ), seguindo as normas propostas por Dorgan Neto ${ }^{22}$. Os impulsos nervosos produzidos pela estimulação cefálica ou na parede gástrica, agem através de neurotransmissores (acetilcolina ou uma substância semelhante à bombesina), que são liberados pelos reflexos nervosos do antro gástrico ${ }^{22}$. Também existe a ação do peptídeo liberador de gastrina (GRP). A distensão da parede gástrica causada pela ingestão alimentar, produz liberação pequena mas significativa de gastrina ${ }^{23}$.

A inibição da liberação da gastrina se deve a vários fatores, podendo ser citadas a inibição adrenérgica, o $\mathrm{pH}$ do conteúdo gástrico e os peptídeos, sendo a somatostatina o mais importante. As células $\mathrm{D}$ se localizam na mucosa antral, próximas das células G. Também são citadas as prostaglandinas, a calcitonina, a secretina, o glucagon, a colecistocinina e o polipeptídeo intestinal vasoativo. Possivelmente o intestino delgado participa do catabolismo da gastrina e também enzimas renais, as endopeptidases. Neste experimento os efeitos da vagotomia não foram notados quando se associou a exclusão gástrica, que eliminou os estímulos mecânicos da fase gástrica da digestão. O modelo experimental empregado associa o blo- queio da ação nervosa vagal e dos estímulos luminais. Uma diminuição da secreção ácida do estômago é esperada, com elevação do $\mathrm{pH}$ no estômago excluído. Consideramos importantes a exclusão tanto da mucosa oxíntica do corpo quanto da mucosa antral, que poderiam equilibrar a resposta funcional encontrada. Este modelo associa também a exclusão duodenal, que fica com suas células $\mathrm{G}$ não estimuladas.

Portela-Gomes et al ${ }^{6}$, em 1987, encontraram uma diminuição da gastrina sérica em seu grupo de ratos operados (controle) e no grupo onde foi realizada a ressecção do antro gástrico. A gastrina sérica aumentou quando foi realizada uma gastro-enteroanastomose no antro e aumentou muito, aproximadamente quatro vezes, após a exclusão antral, já que o efeito inibidor da liberação de gastrina, realizado pelo ácido gástrico é abolido nesta situação. Estes autores não encontraram uma diminuição significativa da gastrina, mesmo após a ressecção de todo o antro, com suas células $\mathrm{G}$. Esta adaptação poderia sugerir que as células $\mathrm{G}$ do duodeno poderiam normalizar a gastrina sérica, sendo citado também que esta normalização dos valores apareceria já após a terceira semana de pós-operatório. Em nosso estudo, a exclusão total do estômago e duodeno do trânsito alimentar levou a uma diminuição da gastrina sérica dos ratos operados. Este achado poderia ser explicado pela exclusão de todo o antro e também de toda a mucosa oxíntica do corpo gástrico, com capacidade de produzir ácido, o que poderia equilibrar esta resposta, impedindo uma estimulação das células $\mathrm{G}$ do antro e do duodeno. No ser humano, Deite ${ }^{24}$ relata que após a derivação gástrica de Griffen, um reservatório gástrico proximal pequeno é necessário, para manter uma quantidade suficiente de células parietais no segmento gástrico distal, evitando a liberação de gastrina pelo antro excluído e o conseqüente desenvolvimento de úlcera péptica, que segundo Schrumpf $e t a l^{11}$, só ocorreria em $1 \%$ a $2 \%$ após as exclusões gástricas.

A análise deste estudo mostra as várias opções que este modelo experimental proporciona e a importância de se desenvolver a linha de pesquisa iniciada, considerando-se que a complexidade e extensão do assunto, nas condições de realização do experimento apresentado, só permitiram uma visão parcial do tema. Os resultados obtidos em ratos, permitemnos concluir que houve uma diminuição significativa do peso e da dosagem de gastrina sérica no animal, mas não houve correlação significativa ou linear entre a porcentagem de queda destes valores. 


\begin{abstract}
Background: Morbid obesity is a chronic disease associated to severe medical complications, causing adverse effects on longevity as well as physical, emotional, social and economical consequences. Both clinical and experimental research have been addressing the surgical treatment. Gastroplasties and gastric bypasses have been developed, resulting in a relatively large gastric pouch where, in some techniques, is totally excluded from gastrointestinal transit. The possible alterations of that segment, transformed into an appendix of the digestory system, represents an interesting research area. Our aim was to evaluate the weight and the alterations of seric gastrin in rats after abdominal truncal vagotomy with exclusion of gastric pouch and duodenum. Methods: Thirty male adult Wistar rats (Rattus Norvegicus Albinus), out of one hundred, submitted to total gastric exclusion, with an average weight of $378.67 \mathrm{~g}$, could be used in our research. The study was complemented by the measurement of seric gastrin using radioimmunoassay $I^{125}$ double antibody gastrin. Results: The weight of all studied rats decreased in average 92, $83 \mathrm{~g}$ (from $378,67 \mathrm{~g}$ to $285,83 \mathrm{~g}$ ) which stands for a reduction of $24,52 \%$. There were significant differences between the initial and final weights $(p<0,001)$. Serum gastrin has also decreased in 21 out of the 30 operated rats from $59,68 \mathrm{pg} / \mathrm{ml}$ to $46,77 \mathrm{pg} / \mathrm{ml}$, corresponding to a decrease of $12,91 \mathrm{pg}(19,73 \%)$ between the two means $(p<0,001)$. Statistical analysis was supposed to evaluate whether there was any decrease in the means of the following variables: weight and gastrin, measured before and after the surgical procedure. The T-Student statistical test was applied to evaluate such differences. Conclusions: There was a significant decrease of weight and serum gastrin after total gastric exclusion.
\end{abstract}

Key Words: Gastroplasty; Gastrins; Gastric bypass; Vagotomy, truncal; Models, animals.

\section{REFERÊNCIAS}

1. Holst JJ, Fahrenkrug J, Stadil F, et al. - Gastrointestinal endocrinology. Scand J Gastroenterol, 1996, 216 (Suppl): 27-38.

2. Walsh JH - "Hormônios gastrointestinais peptídicos e outros peptídios biologicamente ativos". In Sleisenger MH, Fordtran JS - Tratado de Gastroenterologia. $2^{\mathrm{a}}$ Edição. Rio de Janeiro. Interamericana, 1981, pp. 92-132.

3. Asp NG, Gudmand-Hoyer E, Andersen B, et al. Enzyme activities and morphological appearance in functioning and excluded segments of the small intestine after shunt operation for obesity. Gut, 1979, 20(7): 553-558.

4. Dockray GJ - Gastrin, growth, and colon neoplasia. Gut, 2000, 47(6): 747-748.

5. Simões JC, Santis PB, Gama RR, et al. - Colostomia tipo Hartmann em ratos: alterações morfológicas e dosagem de hidroxiprolina. Rev Col Bras Cir, 2000, 27 : 253-9.

6. Portela-Gomes GM, Grimelius L, Johansson H, et al. The effects of gastroenteroanastomosis, antral exclusion and antral resection on the enterochromaffin cells in the rat gastrointestinal tract. Acta Chir Scand, 1987, 153(11-12): 669-675.

7. Young EA, Taylor MM, Taylor MK, et al. - Gastric stapling for morbid obesity: gastrointestinal response in a rat model. Am J Clin Nutr, 1984, 40(2): 293-302.
8. Schafmayer A, Arnold R, Börger HW et al. - The effect of vagotomy on the gastrin level of serum, of antrum mucosa and of gastrin cells. Chir Forum Exp Klin Forsch, 1977, 4: 228-230.

9. Shimoda H, Uchida Y, Murakami S, et al. - Alteration in gastric nerve fibers containing gastrin-releasing peptide in relation to the gastrin-producing cell population after truncal vagotomy in a rat model. Surg Today [serial on line] 1995, [cited 2001 aug 17]. Available from: URL: http://www.ncbi.nlm.nih.gov.

10. Lopasso FP, Rodrigues JG, Alves VA, et al. - Acid secretory response in the late follow-up of proximal gastric vagotomy for duodenal ulcer without Helicobacter pylori eradication. Hepatogastroenterol [serial on line] 1999, jan/feb [cited 2002 jun 18]. Available from: URL: http://www.ncbi.nlm.nih.gov.

11. Schrumpf E, Giercksky KE, Nygaard K, et al. - Gastrin secretion before and after gastric bypass surgery for morbidobesity. Scand J Gastroenterol, 1981, 16(6): 721-725.

12. Campos RV, Pederson RA, Buchan AM, et al. - The effect of dietary restriction on gastrin secretion in the obese Zucker rat. Int J Obes [serial on line] 1990, aug [cited 2001 aug 17]. Available from: URL: http:// www.ncbi.nlm.nih.gov.

13. Arnold R, Frank M, Simon B, et al. - Adaptation and renewal of the endocrine stomach. Scand J Gastroenterol Suppl [serial on line] 1992, [cited 2002 jun 11] Available from: URL: http://www.ncbi.nlm.nih.gov. 
14. McNeely G, Stork J, Macgregor A, et al. - Percutaneous examination of the bypassed stomach. Obes Surg [serial on line] 1991, dec [cited 2001 may 01]. Available from: URL: http://www.ncbi.nlm.nih.gov.

15. Sanioto DL - Sistema digestivo: secreção e digestão. In Aires MM (ed) - Fisiologia. Rio de Janeiro. Guanabara Koogan, 1991, pp.601-629.

16. Sclafani A - Effects of gastrointestinal surgery on ingestive behavior in animals. Gastroenterol Clin North Am [serial on line] 1987, sep [cited 2002 jun 11]. Available from: URL: http://www.ncbi.nlm.nih.gov.

17. Furness JB, Koopmans HS, Robbins HL, et al. - Effects of vagal and splanchnic section on food intake, weigh serum leptin and hypothalamic neuropeptide $\mathrm{Y}$ in rat. Auton Neurosci [serial on line] 2001, sep [cited 2002 jun 11]. Available from: URL: http://www.ncbi.nlm.nih.gov.

18. Hirschowitz BI, Fong $\mathrm{J}$ - Effects of antral vagotomy in dogs on gastrin and gastric secretion with various stimuli. Am J Physiol [serial on line] 1990, jun [cited 2002 jun 18]. Available from: URL: http:// www.ncbi.nlm.nih.gov.

19. Higham A, Noble P, Thopson DG, et al. - Increased sensitivity of gastrin cells to gastric distension following antral denervation in the rat. J Physiol [serial on line] 1997, aug [cited 2001 apr 24]. Available from: URL: http://www.ncbi.nlm.nih.gov.

20. Koop H Schwab E, Arnold R, et al. - Effect of food deprivation on rat gastric somatostatin and gastrin release. Gatroenterol [serial on line] 1982, may [cited 2001 apr 24]. Available from: URL: http:// www.ncbi.nlm.nih.gov.
21. Grossman MI - "Controle da secreção gástrica". In Sleisenger MH, Fordtran JS(eds) - Tratado de Gastroenterologia. 2a Edição. Rio de Janeiro. Interamericana, 1981, pp. 542-545.

22. Dorgan Neto V - Repercussão da ressecção de $80 \%$ de jejuno íleo na população de células $\mathrm{G}$ do antro gástrico (estudo experimental no rato). Dissertação (Mestrado em Cirurgia Geral). São Paulo. Faculdade de Ciências Médicas da Santa Casa de São Paulo, 1990, $65 \mathrm{p}$.

23. Lawton DE, Simcock DC, Candy EJ et al. - Gastrin secretion by ovine antral mucosa in vitro. Comp Biochem Physiol A Mol Integr Physiol [serial on line] 2000, jun [cited 2002 may 04]. Available from: URL: http://www.ncbi.nlm.nih.gov.

24. Deitel M-Overview of operations for morbid obesity. World J Surg, 1998, 22(9): 913-918.

Endereço para correspondência:

Pedro Luiz Squilacci Leme

Av. das Nações Unidas , 561/apto. 52

Bairro Chácara Inglesa

São Bernardo do Campo - SP

CEP: 09726-110

E-mail: gorableme@uol.com.br 